\title{
Um estudo sobre a vitimização para a cidade de São Paulo
}

\author{
REGINA MADALOZZO* \\ GIOVANNA MAIA FURTADO
}

\begin{abstract}
$\sqrt{3}$
A study about the victimization in the city of São Paulo. This paper applies the crime economics theory to Brazilian data. Following Becker (1968), Hinderlang et al. (1978) and Cohen et al. (1981), we tested the microeconomic factors that influence crime and victimization. For this end, the two waves of research of victimization of the Instituto Futuro Brasil, 2003 and 2008, were used in an effort to identify the determinants of victimization and police notification, using probit model. The main results suggest the factors which impact significantly the probability of victimization are the demographic characteristics, economic conditions and personal habits. The models of "life style" and "opportunity" seem to have good performance.

Keywords: economics of crime; victimization; determinants of criminality; binary-choice models (probit); under-reporting.
\end{abstract}

JEL Classification: C35; D69.

O entendimento do crime - o que leva um agente a cometê-lo e o que torna uma pessoa propensa a ser vítima - é essencial para que melhores práticas de combate e prevenção sejam implementadas, para que haja redução das ocorrências de criminalidade e, consequentemente, para aumentar o bem-estar dos indivíduos.

Para se ter uma dimensão do problema: um estudo realizado pelo Banco Interamericano de Desenvolvimento (BID) concluiu que a principal barreira de

\footnotetext{
* Insper — Instituto de Ensino e Pesquisa. E-mails: reginam@insper.edu.br e giovannamff@yahoo.com.br. As autoras agradecem os comentários de Carlos Eduardo Gonçalves, Fábio Gomes e dos participantes do XXXV Encontro Nacional de Economia e dois pareceristas anônimos que muito contribuíram para este trabalho. Também são gratas ao trabalho de assistente de pesquisa de Tânia Lima e Carolina Flores Gomes. Regina Madalozzo informa recebimento de bolsa de produtividade de pesquisa (307513/2007-6) do CNPq. Submetido: Fevereiro 2008: Aprovado: Agosto 2009.
} 
desenvolvimento da América Latina é a violência, com custos ${ }^{1}$ estimados em 84 bilhões de dólares anuais ao Brasil ou 10,5\% do PIB nacional - para El Salvador estima-se 24,9\%, Colômbia, 24,7\%, Venezuela, 11,8\% e México, $12,3 \%$. Outro dado alarmante do estudo é o levantamento da quantidade de anos de vida que são perdidos com a violência: 2,6 na América Latina (sendo 2,5 anos no México, 12,1 em El Salvador, 13,1 na Colômbia, 5,9 no Brasil e 2,8 na Venezuela). Segundo Cerqueira et al. (2007), o custo da violência no Brasil pode ser estimado em 5,09\% do PIB.

As fontes de dados disponíveis referentes à criminalidade que podem ajudar a entender as questões acima são o sistema de justiça criminal (a exemplo dos censos penitenciários), o sistema de segurança pública, o sistema de saúde (dados de hospitais e instituições de perícia médico-legais) e os institutos de pesquisa (que englobam o tópico de vitimização). Mudanças metodológicas, subnotificação, sub-registro e falta de homogeneidade nos dados - temporalmente e entre estados, já que a essência da informação é de responsabilidade de cada estado, não havendo um órgão federal que coordene e divulgue a informação de forma alinhada - são os principais entraves em fontes de segurança pública. Já o sistema de saúde sofre bem menos com os problemas citados anteriormente, mas agregam outro item de preocupação: a restrição dos tipos de crimes documentados (costuma-se ter maior acurácia quando os crimes levam à morte).

Nesse aspecto, o crime pode ser examinado de formas diferentes, desde o que é reportado e registrado pelos órgãos de segurança governamentais, considerando todas as modalidades de crime (roubo, estupro, furto, prostituição, homicídio etc.), passando pelo que chega aos hospitais e órgãos de perícias (que restringe algumas modalidades de crime, pois os condiciona à violência física) e, finalmente, chegando aos dados de vitimização, em que o crime é analisado mais a fundo e mitiga-se o problema de subnotificação. Estas pesquisas são, em geral, realizadas por institutos autônomos, que vão a campo com questionários que buscam extrair do respondente se este sofreu ou não algum tipo de crime e sob quais circunstâncias, identificando suas características, hábitos e a situação do crime. Até recentemente as bases de dados tinham foco no ato criminoso em si (registros oficiais da polícia) ou eram centrados na figura do ofensor (como feito em Mendonça, Loureiro \& Sachsida, 2002; 2003); no entanto, há como nova preocupação o reconhecimento das vítimas, sendo elas o foco do entendimento do crime - ao invés do infrator ou do evento criminoso em específico.

De acordo com MacDonald (2002), o British Crime Survey sugere que apenas $39 \%$ dos crimes são reportados, sendo que as estatísticas de criminalidade podem ser ainda menores quando há diferenças entre o que é reportado

\footnotetext{
${ }^{1}$ Londoño \& Guerrero (1999). Estes custos referem-se a perdas com saúde, perdas materiais, deterioração do consumo e do trabalho e transferências entre as pessoas.
} 
pela vítima e o que é efetivamente registrado pelos órgãos de segurança. O Instituto Futuro Brasil (IFB) revela um índice de subnotificação de $68 \%$ no município de São Paulo, sétimo maior em população do mundo e primeiro do país, coerente com a pesquisa britânica. A importância de utilizarmos as pesquisas de vitimização em contraste com somente os dados oficiais está justamente na maior representatividade das respostas. No caso de São Paulo, como aproximadamente $70 \%$ dos crimes não são reportados, a modelagem e análise da criminalidade que tem como fonte o próprio vitimado nos conduz a informações com maior precisão do que se utilizássemos somente estatísticas públicas.

Entretanto, também existem aspectos não favoráveis ao uso de pesquisas deste gênero. Entre eles, podemos citar a dependência da memória dos respondentes, a especificidade das regiões entrevistadas, a baixa frequência e a falta de homogeneidade. As primeiras pesquisas de vitimização datam do início dos anos 1960, nos Estados Unidos. No Brasil, a primeira pesquisa de abrangência nacional de que se tem conhecimento é a realizada pelo IBGE em 1988, via PNAD. A Tabela 1 mostra as principais pesquisas finalizadas até o momento.

O foco deste trabalho é identificar fatores microeconômicos que influenciam a criminalidade. A contribuição deste trabalho está na combinação de alguns tópicos. O primeiro é utilização de duas ondas da pesquisa de vitimização do IFB, 2003 e 2008, uma fonte recentemente disponibilizada ao público e que conta com a segunda maior amostra do município de São Paulo até então conhecida. Segundo, as variáveis utilizadas da pesquisa abordam uma combinação de fatores não explorada em estudos anteriores que buscam explicar a probabilidade de ocorrência de vários tipos de crime a partir da condição e das características do vitimado e não do infrator. Como terceiro tópico, tem-se o levantamento dos determinantes de notificação qualitativa e quantitativamente - o que não fora aprofundado na literatura nacional.

O trabalho está dividido em três seções. Na primeira, faz-se a revisão bibliográfica, englobando a explicação do tema e as principais análises realizadas. $\mathrm{Na}$ segunda seção, explora-se a pesquisa de vitimização do IFB, focando o município de São Paulo. Por fim, apresenta-se a conclusão.

\section{LITERATURA DE ECONOMIA DO CRIME E VITIMIZAÇÃO}

A abordagem econômica conhecida como economia do crime teve início com Becker (1968). Segundo ele, comete-se um crime se a utilidade esperada do ato criminoso - benefício - for maior do que a utilidade que se teria se o tempo e os recursos fossem usados em outras atividades - seu custo. $\mathrm{O}$ custo inclui não somente o planejamento e a execução, mas também o custo de oportunidade e o custo moral atribuído ao ato de desrespeitar a lei. $\mathrm{O}$ autor tem como hipótese que os criminosos são amantes do risco e são mais sensíveis a alterações na probabilidade de captura do que a alterações no grau de severidade das penas. Nota-se que este modelo constrói apenas a curva de oferta para o 
mercado de crimes, relacionando positivamente o número de crimes com o retorno líquido esperado. O lado da demanda seria estabelecido pelo grau de tolerância da sociedade em relação às atividades ilegais. Tendo como premissa que conforme o número de crimes aumenta essa tolerância diminui, chega-se a uma curva de demanda com inclinação negativa.

Desde os estudos de Becker, é crescente o número de economistas que vêem nos incentivos de ordem econômica fatores determinantes ao envolvimento dos indivíduos com o crime (tais como Ehrlich, 1973; Glaeser, Sacerdote \& Scheinkman, 1996; Levitt, 1998).

A literatura apresenta diversos resultados empíricos para os Estados Unidos. Ehrlich (1973) e Mathieson e Passell (1976) estimaram a elasticidade do crime em relação ao valor esperado da punição. Outra evidência para os Estados Unidos é de que os delinquentes respondem mais a aumentos na probabilidade de serem pegos do que a aumentos no tempo gasto na prisão (Grooger, 1991). Cornwell \& Trumbull (1994) modelam a taxa de criminalidade por distrito em função de variáveis correlacionadas com a captura e punição potencial para o crime. Eles concluem que o mercado de trabalho, através de seus salários médios e das estratégias de justiça criminal, é importante na detenção do crime.

No Brasil, devido principalmente à baixa disponibilidade e divulgação de dados, a quantidade de pesquisas com evidências econométricas é menor. Entretanto, as contribuições e análises vão desde o ponto de vista social, com diversas contribuições qualitativas nas áreas de sociologia, antropologia e ciências políticas, tais como as análises de Adorno (2002), Piquet (1999) e Lima, Peixoto \& Durante (2004) até a análise mais detalhada do modelo econômico (como em Viapiana, 2006). Mendonça (2001) faz uma análise empírica dos determinantes econômicos do crime, para os estados brasileiros utilizando dados em painel no período entre 1985 e 1995. Em seu estudo, ele considera a taxa de homicídios como variável dependente e a renda média das famílias, os gastos públicos com segurança, a taxa de urbanização, o índice de desigualdade de Gini e a taxa de desemprego como variáveis explicativas. Araújo Jr. \& Fajnzylber (2001) estudam os determinantes econômicos e demográficos das taxas de homicídios abrangendo estados brasileiros no período de 1981 a 1996 utilizando informações de seis PNADs do IBGE e o Sistema de Informações sobre Mortalidade (SIM) do DATASUS. Kume (2004) utiliza dados em painel para 26 estados brasileiros, no período de 1984 a 1998, para estimar os determinantes da taxa de criminalidade brasileira via Método Generalizado dos Momentos em Sistema proposto por Blundell \& Bond (1998).

Uma outra abordagem interessante e adotada no Brasil é analisar os determinantes da criminalidade a partir do ponto de vista, ou das características e condições, dos infratores. Em Mendonça, Loureiro \& Sachsida (2002; 2003), os autores utilizam os resultados de pesquisas conduzidas na Penitenciária Estadual de Papuda, Brasília, em 2002, onde quase 700 presidiários foram entrevistados. Estes dois estudos mostram que a teoria econômica que preconiza a 
racionalidade na decisão de cometer um crime é válida. À parte da motivação econômica dos crimes não violentos, características endógenas aos indivíduos, como condição familiar, são determinantes para a ação criminosa.

Em se tratando de dados regionais, Beato, Viegas \& Peixoto (1998) mostram características da criminalidade em Minas Gerais, por regiões administrativas e para algumas cidades, utilizando os registros da Polícia Militar de Minas Gerais para o período de 1986 a 1997. Araújo Jr. \& Fajnzylber (2000), utilizando registros oficiais da Polícia Militar de Minas Gerais e dados de homicídios do Ministério da Saúde, mostram que o grau de educação e o nível de renda per capita impactam negativamente na incidência de crimes contra a pessoa, porém, impactam positivamente em crimes contra a propriedade, o que está alinhado com o encontrado por Piquet \& Fajnzylber (2001), que trabalham com base em pesquisas de vitimização para o Rio de Janeiro e São Paulo. Andrade \& Lisboa (2000) colocam como variável dependente a taxa de homicídio na população masculina em função de variáveis econômicas dos estados de Minas Gerais, Rio de Janeiro e São Paulo para o período de 1981 a 1997. Os autores encontram relação negativa entre o salário real e homicídios e entre desemprego e homicídios para a faixa etária de 15 a 19 anos, o que é coerente com a ideia de custo de oportunidade levantada por Becker (1968). A criminalidade na região metropolitana de São Paulo também foi analisada por Carrera-Fernandez \& Pereira (2000), que estruturam um modelo em que o crime é função linear da taxa de desemprego, do índice de Gini, do rendimento médio do trabalho e das medidas de eficiência da polícia e da justiça criadas pelos autores.

Um outro enfoque possível baseia-se no entendimento do crime do ponto de vista da vítima: o impacto do seu estilo de vida e das oportunidades por ela geradas na probabilidade de ocorrência do evento criminoso. Esta análise vem dos chamados modelos de estilo de vida e de oportunidade. Hinderlang, Gottfredson \& Garofalo (1978) e Cohen, Kluegel \& Land (1981) conduziram alguns estudos com esse arcabouço sociológico. Mencionam-se cinco principais fatores que afetam a probabilidade de vitimização: exposição a situações com maior risco, proximidade física com ambientes mais conturbados, atratividade da vítima e/ou objeto, proteção/segurança da vítima e/ou objeto, propriedades específicas da modalidade criminosa. Seguindo esta abordagem dos modelos de estilo de vida e oportunidades, Piquet \& Fajnzylber (2001) estimaram alguns determinantes da vitimização. Gomes \& Paz (2004) utilizam os dados da Pesquisa de Condição de Vida do SEADE de 1998 para reafirmar a validade destes modelos.

Beato, Viegas \& Peixoto (2004) utilizaram a pesquisa realizada pelo Centro de Estudos em Criminalidade e Segurança Pública (CRISP) entre fevereiro e março de 2002, no município de Belo Horizonte, para estimar os determinantes de vitimização baseados também em pesquisas de estilo de vida. A pesquisa contém informações sobre as modalidades furto, roubo e agressão e, através das condições e características que as vítimas reportam a respeito de 
crimes sofridos, interpretam as probabilidades de novas ocorrências. Os autores mostram que pessoas mais velhas têm menor chance de sofrer agressão que os mais jovens. Para os crimes economicamente motivados, características pessoais não são significativas. Ser vítima está vinculado a hábitos e características da vizinhança, tais como transitar em locais públicos em horários de maior fluxo e à noite, morar em locais onde há muitos prédios abandonados e onde se ouve barulho de tiros.

Neste estudo, usaremos dados das duas ondas da Pesquisa de Vitimização em São Paulo - pesquisa que é descrita na próxima seção - para analisarmos os determinantes da criminalidade do ponto de vista da vítima. Em termos de políticas públicas, é mais clara a influência do Estado em fatores que aumentem o custo em se cometer um crime do que em ações que possibilitem os indivíduos a não serem vitimizados. Entretanto, a ação individual preventiva pode ter tanto efeitos na redução da vitimização quanto na melhoria no Estado de bem-estar da população com a diminuição da violência.

\section{PESQUISA DE VITIMIZAÇÃO EM SÃO PAULO}

Para o presente estudo foi utilizada a base de dados sobre vitimização do Instituto Futuro Brasil. A primeira onda desta pesquisa foi coletada no ano de 2003, com pesquisa realizada em 5 mil domicílios (20 mil pessoas) do município de São Paulo seguindo o modelo estabelecido pelo National Victimization Survey dos Estados Unidos. Em cada domicílio, a entrevista era concedida preferencialmente pelo responsável pelo mesmo e abrangia residentes com mais de 16 anos. Em 2008, cinco anos após a primeira onda, o Instituto Futuro Brasil conduziu nova pesquisa, utilizando um questionário muito parecido com o da pesquisa anterior, ${ }^{2}$ para 3 mil domicilíos também na região metropolitana do município de São Paulo.

A amostragem e o campo das pesquisas foram conduzidos pelo Instituto Ipsos. As amostras seguem a divisão operacional da Secretaria de Segurança Pública de São Paulo e o nível de criminalidade da seccional. O questionário contava com um módulo de vitimização e recurso à polícia e outro sobre a percepção de risco e medo da violência. A Tabela 2 contém informações básicas das variáveis utilizadas nos modelos que seguem. Para todos os modelos, usamos somente as informações relacionadas aos respondentes da pesquisa. A alternativa seria utilizarmos as respostas para todos os integrantes do domicílio, mas esta escolha implicaria em um maior risco de viés nas respostas, visto que não necessariamente o respondente tem todas as informações relevantes

\footnotetext{
${ }^{2}$ As alterações no questionário foram efetuadas somente nas perguntas em que se verificou uma dificuldade maior na resposta do pesquisado ou a inclusão de um módulo sobre a percepção da desordem na comunidade. Entretanto, manteve-se como base absoluta a pesquisa realizada em 2003.
} 
para o nosso modelo. Desta forma, optamos por uma amostra menor, mas com uma qualidade superior nas informações concedidas. Apesar de concatenarmos os dados das duas ondas para os modelos - e controlar para o ano da pesquisa -, na Tabela 2 colocamos os dados separados para cada ano. Conforme se pode perceber, poucas diferenças são relevantes entre as duas amostras.

Para estimar o risco individual de vitimização nas modalidades de crime mencionadas, foi usado o modelo probit, considerando como variável binária dependente a ocorrência ou não de determinado crime em função de características da pessoa, de seu estilo de vida e das oportunidades geradas pela vítima para concretização do crime.

O modelo probit, que surge de uma função distribuição acumulada de probabilidade da normal-padrão, é usado para variáveis dicotômicas e define-se por:

$$
\operatorname{Pr}\left(y_{i}=1\right)=\phi\left(X_{i} \beta\right)=\int_{-\infty}^{x_{i} \beta} \frac{1}{\sqrt{2 \pi}} \exp \left(-\frac{z^{2}}{2}\right) d z
$$

em que $\operatorname{Pr}\left(y_{i}=1\right)$ simbolizará a probabilidade de ocorrência de certa modalidade de crime para o indivíduo $i ; \operatorname{Pr}\left(y_{i}=1\right)$ é a função de distribuição acumulada de probabilidade da normal-padrão; $X$, o vetor de variáveis explicativas; $\beta$ os coeficientes das variáveis independentes; $z$ representa variáveis normais padronizadas, em que $z \sim N(0,1)$. Pode-se interpretar este modelo como uma regressão já que:

$$
E\left(y \mid X_{i}\right)=0\left[1-F\left(X_{i} \beta\right)\right]+1\left[F\left(X_{i} \beta\right)\right]=F\left(X_{i} \beta\right)
$$

Para tornar a interpretação mais direta, as estimativas a seguir estão expostas em forma de efeito marginal. Para a aplicação da teoria, algumas informações da pesquisa de vitimização foram selecionadas como proxies dos fatores mencionados. A exposição da possível vítima está representada pelas variáveis: sexo, idade, dummy de migração, dummy de imigração, religião, estado conjugal, condição no mercado de trabalho, dummy de trabalho fora do domicílio, quantidade de pessoas que moram na residência, tempo que se mora na residência, consumo de bebidas alcoólicas e hábitos diversos. A proximidade tem muitas variáveis em comum com a exposição, abrangendo: sexo, idade, dummy de migração, dummy de imigração, religião, escolaridade, condição no mercado de trabalho, dummy de trabalho fora do domicílio, zona da residência, indicativo de ter ou não carro e hábitos diversos. Como proxies da atratividade tem-se: dummy de migração, condição econômica, condição no mercado de trabalho, posição no mercado de trabalho, localização do domicílio, indicativo de ter ou não carro. Finalmente, foram utilizadas as seguintes variáveis para representar a capacidade de proteção/segurança: dummy de imigração, religião, condição econômica, escolaridade, posição no mercado de trabalho, quantidade de pessoas que moram na residência, indicativo de morar em casa ou apartamento, localização do domicílio, zona da residência, in- 
dicativo de seguro, porte de arma e consumo de bebidas alcoólicas. Muitas das variáveis selecionadas são compartilhadas por mais de um fator e podem ter efeito ambíguo. Resta verificar que efeito prevalece dependendo da modalidade de crime estimada.

Isto posto, para as estimações dos determinantes de vitimização a seguir expostas, partimos de um modelo que é uma adaptação do modelo de Gomes $\&$ Paz (2004) e complementamos com variáveis adicionais disponíveis na pesquisa do IFB. Montamos um modelo para cada tipo de crime e utilizamos as bases de 2003 e 2008 concatenadas. Para medir o efeito temporal das respostas, incluímos uma variável dummy que assume valor zero se a entrevista é referente à onda de 2003 e um para o caso da entrevista pertencer à onda de 2008 da pesquisa de vitimização.

\section{Roubo ou furto na residência}

Dos entrevistados, $19 \%$ declaram terem sido vítimas de roubo ou furto na residência. A Tabela 3 mostra o modelo estimado. Na penúltima coluna, reportamos o coeficiente estimado através do modelo probit. A última coluna reporta o efeito marginal da variável para a média das outras características. Nesta coluna, reportamos somente o efeito para as variáveis que foram significativas.

As variáveis relevantes para este tipo de vitimização foram: a média da idade no domicílio, pertencer às classes de condição econômica mais elevadas, não residir em favelas, residir em imóvel alugado e possuir arma. Com relação à média de idade, a cada um ano de aumento na média da idade dos moradores do domicílio diminui-se em $0,2 \%$ a probabilidade de ter roubo ou furto na residência. Isso pode ser explicado pelo fator de risco inerente da presença de crianças e/ou adolescentes em casa, pois estes geralmente têm menor preocupação com a segurança do imóvel e implicando em maior probabilidade de deixar o imóvel exposto para entrada de infratores.

As classes A e B apresentam um maior risco de terem suas casas roubadas ou furtadas que varia entre $1,6 \%$ e 3,8\% em comparação com as classes C, D e E. Claramente, a motivação econômica é o forte deste resultado. Residências onde os moradores pertençam a classes econômicas privilegiadas aumentam o benefício esperado do roubo (Viapiana, 2006). A localização do domicílio, relacionada com este poder aquisitivo, também apresentou relevância nas estimativas. Residir próximo a favelas ou não ter favelas perto da residência aumenta em aproximadamente $3 \%$ a probabilidade de o domicílio ser roubado ou furtado. A categoria de comparação é o domicílio ser dentro de uma favela; desta forma, a explicação para a significância desta variável está relacionada não somente ao poder aquisitivo de residências fora da favela ser mais interessante ao infrator, mas também pode ser relacionada com o poder paralelo de controladores informais da favela (e.g., traficantes ou milícias).

Residências alugadas têm probabilidade $2,3 \%$ superior de sofrerem este 
tipo de vitimização do que imóveis próprios. O investimento em segurança em domicílios próprios pode explicar este diferencial, com o morador sendo mais cauteloso em prevenir entrada de infratores em sua residência caso esta seja própria do que se fosse alugada; visto que este adicional de segurança tem caráter exclusivo à residência e não existem incentivos nem para que proprietário do imóvel alugado os coloquem, nem os inquilinos (pois pode ser um custo sem retorno ao deixar o imóvel).

Por fim, a existência de armas no domicílio aumenta em 5,1\% a chance do mesmo ser roubado ou furtado. ${ }^{3}$ Uma explicação para o fato é que a presença de armas seja justificada pelo maior risco e, dada a racionalidade do morador, esta ameaça é factual. Um detalhe interessante é que não podemos identificar quando a arma foi adquirida. Desta forma, a sugestão para estudos futuros é a inclusão de perguntas que possibilitem ao pesquisador identificar se a arma foi comprada antes da vitimização ocorrer ou se ela é um resultado $\mathrm{da}$ insegurança sentida pelo morador no momento em que foi vitimado.

\section{Roubo ou furto de carro}

No tipo de crime com maior grau de notificação, observa-se que os modelos teóricos de estilo de vida e oportunidade dão indícios de validade mais uma vez. O modelo estimado encontra-se na Tabela $4 \mathrm{e}$, da mesma forma que a tabela anterior, relatamos tanto o coeficiente estimado como seu efeito marginal. Ressalta-se a diminuição do número de observações para estas estimativas, pois somente utilizamos como base indivíduos que tiveram posse de automóvel e que, desta forma, estavam passíveis a serem vitimados. Somente três características referentes ao proprietário do automóvel tiveram relação com a probabilidade do mesmo ser roubado ou furtado: seu estado civil, classe econômica e gastos com seguros.

Indivíduos que convivam em união estável (oposto a indivíduos solteiros, divorciados ou viúvos) apresentam 3,5\% menos chance de terem seus automóveis roubados. Não encontramos o mesmo resultado para indivíduos casados, embora o coeficiente estimado para esta variável também seja negativo. A explicação para este efeito é que indivíduos em algum tipo de união estável tenham um comportamento menos arriscado aos seus bens e, desta forma, diminuam de forma significante a probabilidade de serem vitimados.

A significância de uma faixa específica de renda, A, na diminuição da chance de se tornar vítima tem coerência na medida em que os veículos das classes econômicas mais altas tendem a ser menos "líquidos" no mercado de revenda - além de terem menor exposição e proximidade com o criminoso.

\footnotetext{
${ }^{3}$ Em Vipiana (2006) temos o resultado de que a presença de um maior número de armas nos domicílios diminui a incidência de homicídios. Como o crime analisado é diferente, podemos perceber um impacto diverso na presente análise.
} 
Nessas circunstâncias, se houver o delito, ao permanecer com o carro ou moto ou tentar vendê-los, o delinquente é mais facilmente descoberto, o que o desestimula a roubá-lo ou furtá-lo. Indivíduos pertencentes à classe A2 - comparados com classes $\mathrm{C}, \mathrm{D}$ e E - tem aproximadamente $5 \%$ de redução na probabilidade de terem seus veículos subtraídos.

Por fim, o gasto com seguro - da mesma forma que o efeito de possuir armas, na regressão anterior - implica em um aumento de 2,3\% na probabilidade de ter o automóvel roubado/furtado. A motivação para este investimento pode estar no valor do bem - que fornece maior incentivo ao infrator para roubá-lo, como também na proteção em caso de subtração do mesmo, resultando em maior perda para o proprietário. Por fim, podemos relacionar este resultado com as teorias de moral hazard, onde o indivíduo que tem seguro apresenta um comportamento com maior risco por já estar segurado (Ehrlich \& Becker, 1972).

\section{Agressão física}

Enquanto os crimes estimados anteriormente têm essencialmente motivação material, essa modalidade representa casos de vitimização onde o delito que não tenha necessariamente motivação material - o que pode mudar o perfil que foi relativamente homogêneo até então para os demais atos de criminalidade. A Tabela 5 mostra os resultados das estimações.

As variáveis relevantes para a probabilidade de vitimização por agressão física foram referentes ao estado civil, ao porte de armas, a maior exposição via circulação para fins sociais e, pela primeira vez, houve significante diferença entre a probabilidade de ocorrência deste tipo de crime entre os dois anos estudados. De acordo com nossas estimativas, para os dados pesquisados em 2008 calculamos 1,1\% menos chances de ocorrência de agressão física do que para os coletados em 2003.

O fato do indivíduo ser casado diminui em 1,8\% a probabilidade de sofrer agressão. Novamente, comparando com os dados de roubo de automóvel, o fato do indivíduo ter uma relação estável com outra pessoa faz com que ele se exponha menos a fatores de risco, diminuindo assim sua chance de vitimização. Conforme indicaria a teoria, o fato de possuir uma arma aumenta em $5 \%$ a probabilidade do indivíduo sofrer agressão física. Provavelmente este fator sofre a interferência da endogeneidade do tipo de pessoa. Pessoas mais agressivas têm maior probabilidade de ter armas do que pessoas com o perfil mais calmo e, desta forma, o mesmo fator que o impulsiona a comprar uma arma pode aumentar suas chances de participar de eventos que resultem nesta agressão.

Conforme previsto pelas teorias de estilo de vida e de oportunidade, indivíduos que frequentam bares, shows ou festas de rua têm aproximadamente $1 \%$ maior chance de sofrer agressões físicas do que indivíduos que não o fazem. A explicação para este resultado está na exposição a grupos maiores de 
pessoas em lugares públicos criando a possibilidade de conflito entre indivíduos e a consequente violência física. Ressalta-se a não influência significante do consumo de bebidas alcoólicas na probabilidade de ser agredido fisicamente. Este fator se deve pelo fato de estarmos observando o comportamento da possível vítima que não necessariamente se confunde com o papel de agressor. Caso estimássemos o comportamento do agressor (com dados semelhantes aos de Mendonça, Loureiro \& Sachsida, 2002; 2003), então poderíamos analisar o efeito do consumo de álcool no nível de violência física.

Para todos os modelos descritos temos resultados em consonância com as teorias de crime, bem como de estilo de vida e oportunidade. Desta forma, observando as evidências pelo ponto de vista do vitimado podemos apontar fatores que determinam maior ou menor probabilidade de sofrer algum tipo de violência (econômica ou física) dadas as características do indivíduo e assim, fornecer informações que permitam uma ação preventiva mais efetiva da vitimização em potencial.

\section{Determinantes da notificação}

Para complementar o descritivo de causas de subnotificação da outra seção, estimou-se, via probit, a probabilidade de a vítima informar a ocorrência do crime à polícia segundo as seguintes variáveis explicativas: sexo, média da idade no domicílio, etnia, religião, dummy migrante, condição econômica, indicativo de morar em casa ou apartamento, quantidade de pessoas na residência, tempo em que moram no domicílio, localização do domicílio, tipo de imóvel, gatos com seguro, porte de arma, tipos de crimes sofridos e quantidade de vitimizações para notificação de roubo à residência. Com relação à notificação de roubo de carros, utilizamos as variáveis: sexo, idade, etnia, religião, número de vezes que teve o carro furtado e dummy de identificação do infrator. Por hipótese, admite-se que os efeitos das variáveis escolhidas são diferentes para cada tipo de vitimização sofrida. Desta forma, elaboramos um modelo para notificação de roubo ou furto à residência e outro modelo para notificação de roubo ou furto de automóvel. A vitimização por agressão física, dado seu reduzido número de observações, não pôde ser avaliada.

Para estimar o modelo, partiu-se da mesma linha citada nos modelos de vitimização: espera-se que as vítimas optem por notificar as ocorrências quando os benefícios forem maiores que os custos. Os benefícios são representados pela probabilidade de recuperar o bem ou resolver o problema vezes o valor do bem ou da resolução mais a utilidade esperada de ter o criminoso preso. A probabilidade de recuperação do bem é função da qualidade da polícia e o custo da vítima depende de quão acessível e prático está o reporte à polícia. Entretanto, não temos acesso a variáveis que lidem com estas questões. Desta forma, optamos por utilizar uma proxy do valor do bem que é um conjunto de dummies de tipo de crime sofrido e, em relação à utilidade esperada de ver o criminoso preso, utilizou-se a variável sobre a identificação do criminoso. 
Pressupõe-se custo constante de notificação independente do número de crimes sofridos, pois o indivíduo precisará passar pela mesma burocracia até o registro final do mesmo. Com esta lógica, poder-se-ia testar qual a política ótima: aumentar a probabilidade de recuperação ou a esperança de capturar o criminoso ou reduzir os custos de notificação, dado que os outros fatores não seriam controláveis pelas autoridades.

As Tabelas 6 e 7 reportam os coeficientes estimados para os modelos através do probit e também o efeito marginal de cada variável significante para esta notificação. Como os modelos de notificação usam como amostra somente indivíduos que sofreram este tipo de notificação e então tiveram a oportunidade de decidir entre notificar ou não a ocorrência, o número de observações é bastante reduzido (142 observações para roubo/furto de residência e 118 observações para roubo/furto de automóvel).

A subnotificação para roubo/furto de residências é influenciada basicamente pelo tipo de imóvel em que o indivíduo reside. Caso o imóvel seja alugado, a notificação tem sua probabilidade reduzida em 15,2\% em comparação a imóveis próprios. Este resultado conciliado com o que encontramos na Tabela 3 indica que não somente imóveis alugados têm maior probabilidade de serem roubados/furtados, mas também que a notificação para a polícia é bastante abaixo da real ocorrência deste tipo de crime.

Com relação à notificação de roubo/furto de veículo, utilizamos as características pessoas do proprietário do automóvel e da situação de vitimização (como o número de vezes em que teve o automóvel roubado/furtado e a identificação do assaltante) para medir o impacto na notificação. Somente duas variáveis foram relevantes: o sexo do proprietário (a um nível de $15 \%$ ) e o não engajamento do indivíduo em nenhum tipo de religião. Homens apresentam $11 \%$ menos chance de reportarem à polícia o roubo ou furto de seus veículos. Isso pode estar relacionado tanto com a inexistência de seguro sobre o veículo - pois homens pagam seguros mais elevados do que as mulheres e, dado este efeito-preço, a probabilidade de efetuar seguros é mais reduzida - , como também pela possibilidade de não acreditar que o bem possa ser recuperado. Com relação à religião, indivíduos que não declararam nenhum tipo de religião apresentaram probabilidade $22 \%$ menor de notificar roubo/furto de seus automóveis. Esta influência também pode ser relacionada com características intrínsecas do indivíduo que o levaram a acreditar na menor chance de recuperação do bem ou na solução de seu problema pelas vias legais.

\section{CONCLUSÃO}

Os modelos apresentados buscaram aplicar duas das principais frentes da teoria de economia do crime (Becker, 1968; Hinderlang, Gottfredson \& Garofalo, 1978; Cohen, Kluegel \& Land,1981). Constatou-se, via regressões probit, que o estilo de vida dos indivíduos e as oportunidades que estes geram são 
essenciais para a explicação dos crimes que sofrem, sejam eles economicamente motivados ou não. A probabilidade de vitimização aumenta quanto maior a exposição e atratividade da possível vítima e diminui conforme o indivíduo se protege. As informações selecionadas da pesquisa do IFB e sua explicação no aumento ou redução da probabilidade de vitimização corroboraram os modelos teóricos. Em geral, as variáveis relacionadas à possível vítima que se mostraram significantes foram: idade, religião, classe social, condições de moradia e hábitos relacionados aos lugares que frequenta, porte de armas, estado civil, gasto com seguro e localização do domicílio.

Ainda, considerando os dados de notificação, vê-se que o percentual reportado à polícia é bastante baixo e que, para as vítimas, não só a esperança de recuperar o que lhes foi tirado, como também a expectativa de que o criminoso seja punido pesam na decisão de registrar a ocorrência criminosa. Crimes em que se imagina que a polícia possa ajudar a vítima de alguma forma findam por ter índices de notificação maiores. Urgem, portanto, políticas que possam estabelecer canais que aumentem o reporte para estudos mais abrangentes e, consequentemente, que possam suportar políticas mais eficazes. Com melhores fontes de dados, políticas públicas mais eficientes e ações individuais de prevenção, os custos com a criminalidade diminuem, há mitigação dos crimes e aumento de bem-estar da população.

\section{REFERÊNCIAS BIBLIOGRÁFICAS}

ADORNO, Sérgio (2002) "Exclusão socioeconômica e violência urbana”, Sociologias. Porto Alegre. n. 8. p. 84-135.

ANDRADE, Mônica. V.; LISBOA, Marcos. (2000) "Desesperança de vida: homicídio em Minas Gerais, Rio de Janeiro e São Paulo: 1981 a 1997”, in HENRIQUES, Ricardo, org. Desigualdade e Pobreza no Brasil. Rio de Janeiro: IPEA.

ARAÚJO JR. Ari F.; FAJNZYLBER, Pablo (2000) “Crime e economia: Um estudo das microregiões mineiras”, Revista Econômica do Nordeste, Fortaleza, v. 31, n. especial.

Violência e Criminalidade (2001), in LISBOA, Marcos; MENEZES FILHO, Naércio, orgs. Microeconomia e Sociedade no Brasil, Rio de Janeiro, Editora Contracapa.

BEATO, Cláudio C.; VIEGAS, Mônica; PEIXOTO, Betânia (1998) Criminalidade Violenta em Minas Gerais - 1986 a 1997. Belo Horizonte, UFMG, Mimeo.

BEATO, Cláudio C.; VIEGAS, Mônica; PEIXOTO, Betânia T. (2004) "Crime, oportunidade e vitimização”, Revista Brasileira de Ciências Sociais, vol. 19 (55): 73-89.

BECKER, Gary (1968) “Crime and punishment: An economic approach", Journal of Political Economy, vol. 76, 169-217.

BLUNDELL, Richard; BOND, Stephen. (1998) "Initial conditions and moment restrictions in dynamic panel data models", Journal of Econometrics, 104.

CARRERA-FERNANDEZ, José; PEREIRA, Rogério (2000) “A criminalidade na região policial da grande São Paulo sob a ótica da economia na criminalidade”, Revista Econômica do Nordeste, vol. 31, n. especial.

CERQUEIRA, Daniel; CARVALHO, Alexandre; LOBÃO, Waldir e RODRIGUES, Rute (2007) “Análise dos custos e consequências da violência no Brasil”. Texto para discussão IPEA no. 1284.

COHEN, Lawrence; KLUEGEL, James R.; LAND, Kenneth C. (1981) "Social inequality and preda- 
tory criminal victimization: An exposition and test of a formal theory”, American Sociological Review, vol. 46: 505-524.

CORNWELL, Christopher; TRUMBULL, William N. (1994) "Estimating the economic model of crime with panel data", The Review of Economics and Statistics, vol. 76: 360-366.

EHRLICH, Isaac (1973) "Participation in illegitimate activities: A theoretical and empirical investigation", Journal of Political Economy, vol. 81: 521-565.

EHRLICH, Isaac; BECKER, Gary (1972) "Market insurance, self-insurance and self-protection", Journal of Political Economy, vol 80 (4): 623-658.

GLAESER, EDWARD L.; SACERDOTE, Bruno; SCHEINKMAN, José A. (1996) "Crime and social interactions", Quarterly Journal of Economics, vol. 111: 507-548.

GOMES, Fábio Augusto R.; PAZ, Lourenço S. (2004) “The determinant of criminal victimization in São Paulo state", in XXXII Encontro Nacional de Economia. Anais do XXXII Encontro Nacional de Economia, João Pessoa., 2004.

GROGGER, Jeff (1991) “Certainty vs. severity of punishment”, Economic Inquiry, vol. 29: 297-309.

HINDELANG, Michael J.; GOTTFREDSON, Michael R.; GAROFALO, James (1978) Victims of personal crime: An empirical foundation for a theory of personal victimization. Cambridge, Ballinger Publishing Company.

KUME, Leandro (2004) "Uma estimativa dos determinantes da taxa de criminalidade brasileira: uma aplicação em painel dinâmico", in Associação Nacional dos Centros de Pós-Graduação em Economia. Anais do XXXII Encontro Nacional de Economia, São Paulo: ANPEC, 2004. Disponível em http://www.anpec.org.br/encontro2004/artigos/A04A148.pdf

LEVITT, Steven (1998) "Why do increased arrest rates appear to reduce crime: deterrence, incapacitation, or measurement error?" Economic Inquiry, vol. 36:. 353-372.

LIMA, Renato S.; PEIXOTO, Betânia T.; DURANTE, Marcelo O. (2004) "Metodologias e criminalidade violenta no Brasil”, São Paulo em Perspectiva, vol. 18 (1): 13-21.

LONDOÑO, J. L., GUERRERO, R. (1999) Violencia en America Latina: epidemiologia e costos. Washington, D.C.: Banco Interamericano de Desarrollo, Oficina del Economista Principal.

MACDONALD, Ziggy (2002) "Official crime statistics: their use and interpretation", The Economic Journal, vol. 112 (477): F85-F106.

MATHIESON, Donald, PASSELL, Peter (1976) "Homicide and robbery in New York city: An economic model”, Journal of Legal Studies, vol. 6: 83-98.

MENDONÇA, Mário J. C. (2001) Um Modelo de Criminalidade para o Caso Brasileiro. Brasília: IPEA, Mimeo.

MENDONÇA, Mário; LOUREIRO, Paulo e SACHSIDA, Adolfo (2002) “Interação social e crimes violentos: uma análise empírica a partir dos dados do presídio de Papuda”, Estudos Econômicos, Vol. 32 (4): 612-641.

MENDONÇA, Mário; LOUREIRO, Paulo e SACHSIDA, Adolfo (2003) "Criminalidade e interação social” Texto para Discussão IPEA no. 968.

PIQUET, Leandro (1999) Determinantes do Crime na América Latina: Rio de Janeiro e São Paulo. São Paulo, Universidade de São Paulo, Mimeo.

PIQUET, Leandro; FAJNZYLBER, Pablo (2001) “A criminalidade nas regiões metropolitanas do Rio de Janeiro e São Paulo: Determinantes da vitimização e políticas públicas”, in FAJNZYLBER, Pablo; LEDERMAN, Daniel; LOAYZA, Norman, orgs. Crime e Violência na América Latina, Banco Mundial/Alfaomega.

VIAPIANA, Luiz Tadeu (2006) Economia do Crime: Uma Explicação para a Formação do Criminoso. Porto Alegre: AGE Editora. 
Tabela 1: Principais Pesquisas de Vitimização Divulgadas

\begin{tabular}{|c|c|c|c|}
\hline Pesquisas/Realizadores & Ano & Região & Amostra \\
\hline \multirow{3}{*}{$\begin{array}{l}\text { PNAD(Pesquisa Nacional por Amostra } \\
\text { de Domicílios) do IBGE }\end{array}$} & 1988 & Brasil & $\begin{array}{l}81.628 \\
\text { domicílios }\end{array}$ \\
\hline & 1992 & RJ - Município & 1.000 pessoas \\
\hline & 1996 & RJ - Município & 1.001 pessoas \\
\hline \multirow{2}{*}{$\begin{array}{l}\text { ILANUD (Instituto Americano das } \\
\text { Nações Unidas para Prevenção do } \\
\text { Delito e Tratamento do Delinquente) }\end{array}$} & 1997 & SP - Município & 2.469 pessoas \\
\hline & 2002 & $\begin{array}{l}\text { Recife, Rio de Janeiro, } \\
\text { São Paulo e Vitória }\end{array}$ & 2.800 pessoas \\
\hline $\begin{array}{l}\text { ISER (Instituto de Estudos da } \\
\text { Religião)/PAHO (Pan American } \\
\text { Health Organization) }\end{array}$ & 1996 & RJ - Município & 1.126 pessoas \\
\hline $\begin{array}{l}\text { ISER (Instituto de Estudos da Religião) } \\
\quad \text { / FGV (Fundação Getulio Vargas) }\end{array}$ & 1996 & $\begin{array}{l}\text { RJ - Região } \\
\text { Metropolitana }\end{array}$ & $\begin{array}{l}16.763 \text { pessoas; } \\
6.873 \text { domicílios }\end{array}$ \\
\hline $\begin{array}{l}\text { SEADE (Sistema Estadual } \\
\text { de Análise de Dados) }\end{array}$ & 1998 & $\begin{array}{c}\text { SP - Região } \\
\text { Metropolitana e } \\
\text { municípios com mais } \\
\text { de } 50 \text { mil habitantes }\end{array}$ & 14.000 pessoas \\
\hline USP (Universidade de São Paulo) & 1999 & $\begin{array}{l}\text { SP - Região } \\
\text { Metropolitana }\end{array}$ & 1.000 pessoas \\
\hline $\begin{array}{l}\text { CRISP (Centro de Estudos } \\
\text { de Criminalidade e Segurança } \\
\text { Pública) - UFMG }\end{array}$ & 2002 & Belo Horizonte & 4.000 pessoas \\
\hline IFB (Instituto Futuro Brasil) & 2003 & SP - Município & $\begin{array}{l}20.000 \text { pessoas; } \\
5.000 \text { domicílios }\end{array}$ \\
\hline $\begin{array}{l}\text { IBPS (Instituto Brasileiro } \\
\text { de Pesquisa Social) }\end{array}$ & 2005 & RJ - Município & 1.100 pessoas \\
\hline ISP (Instituto de Segurança Pública) & 2007 & $\begin{array}{l}\text { RJ - Região } \\
\text { Metropolitana }\end{array}$ & 5.000 pessoas \\
\hline
\end{tabular}

Tabela 2: Análise Descritiva das Principais Variáveis Utilizadas

Painel A: Variáveis Contínuas

\begin{tabular}{ccc}
\hline Variável & 2003 & 2008 \\
\hline Idade do Respondente & 37,28 & 39,51 \\
& $(16,37)$ & $(17,10)$ \\
Quantidade de Pessoas & 4,12 & 3,91 \\
Residentes no Domicílio & $(1,77)$ & $(1,75)$ \\
Tempo de Moradia no & 13,86 & 15,34 \\
Domicílio (em anos) & $(12,98)$ & $(13,33)$ \\
\hline
\end{tabular}




\begin{tabular}{|c|c|c|}
\hline Variável & 2003 & 2008 \\
\hline \multicolumn{3}{|l|}{ Sexo: } \\
\hline Masculino & 52,70 & 48,74 \\
\hline Feminino & 47,30 & 51,26 \\
\hline \multicolumn{3}{|l|}{ Etnia: } \\
\hline Branca & 58,30 & 56,45 \\
\hline Parda & 28,82 & 12,43 \\
\hline Preta & 9,67 & 28,55 \\
\hline Indígena & 1,72 & 0,81 \\
\hline Amarela & 1,50 & 1,76 \\
\hline \multicolumn{3}{|l|}{ Religião: } \\
\hline Evangélico/Pentecostal & 12,49 & 21,56 \\
\hline Evangélico Não Pentecostal & 7,53 & 2,33 \\
\hline Religião de Origem Africana & 1,09 & 0,71 \\
\hline Espírita & 6,01 & 6,98 \\
\hline Católica Romana & 59,96 & 58,33 \\
\hline Judeu & 0,51 & 0,10 \\
\hline Muçulmano & 0,04 & 0,03 \\
\hline Outra religião & 4,05 & 0,17 \\
\hline Não tem religião & 7,74 & 9,78 \\
\hline Ateu1 & 0,58 & - \\
\hline \multicolumn{3}{|l|}{ Migrante } \\
\hline Não & 63,82 & 68,33 \\
\hline Sim & 36,18 & 31,67 \\
\hline \multicolumn{3}{|l|}{ Estado conjugal: } \\
\hline Casado(a) & 45,05 & 40,67 \\
\hline União Consensual/informal & 13,21 & 9,23 \\
\hline Solteiro (a) & 34,21 & 43,91 \\
\hline Divorciado(a)/Desquitado(a) & 1,39 & 1,37 \\
\hline Separado(a) & 2,32 & 2,08 \\
\hline Viúvo(a) & 3,82 & 2,74 \\
\hline \multicolumn{3}{|l|}{ Classe Social2: } \\
\hline A1 & 0,13 & 0,10 \\
\hline $\mathrm{A} 2$ & 3,17 & 0,36 \\
\hline
\end{tabular}




\begin{tabular}{|c|c|c|}
\hline Variável & 2003 & 2008 \\
\hline B1 & 10,03 & 6,92 \\
\hline B2 & 20,22 & 26,73 \\
\hline $\mathrm{C} 1$ & 45,80 & 33,15 \\
\hline $\mathrm{C} 2$ & - & 23,83 \\
\hline $\mathrm{D}$ & 20,09 & 8,20 \\
\hline E & 0,55 & 0,20 \\
\hline \multicolumn{3}{|l|}{ Educação: } \\
\hline Nenhuma & 3,45 & 1,32 \\
\hline De 1 a 8 anos de estudo & 44,49 & 36,92 \\
\hline De 9 a 11 anos de estudo & 37,97 & 45,46 \\
\hline 12 ou mais anos de estudo & 14,09 & 16,30 \\
\hline Tamanho da amostra & 4.882 & 2.967 \\
\hline
\end{tabular}

Notas: Em 2008, a categoria de religião "ateu" foi excluída. Para classificação de classes sociais, utilizamos o critério divulgado pela ABEP (Associação Brasileira de Empresas de Pesquisa). Este critério foi alterado em 2008, incluindo a classe $\mathrm{C} 2$.

Tabela 3: Probit (y=Roubo ou Furto na Residência) ${ }^{1}$

\begin{tabular}{lccc}
\hline & Masculino & $\begin{array}{c}\text { Coeficiente } \\
\text { Estimado }\end{array}$ & $\begin{array}{c}\text { Efeito Marginal } \\
\text { da Variável na } \\
\text { Média }^{3}\end{array}$ \\
\hline $\begin{array}{l}\text { Sexo } \\
\text { Média de idade no domicílio }\end{array}$ & 0,020 & $-0,2 \%$ \\
$\begin{array}{l}\text { Quadrado da média de idade no domicílio } \\
\text { Etnia }\end{array}$ & Preta/Parda & $-0,018^{*}$ & \\
Indígena & 0,0001 & \\
Religião & Amarela & $-0,089$ & \\
Migrante & Sem religião & $-0,213$ & \\
Condição Econômica & A1 ${ }^{2}$ & $-0,077$ & \\
& A2 & 0,019 & $3,8 \%$ \\
& B1 & $-0,019$ & $2,7 \%$ \\
Bempo de residência & B2 & $0,263^{*}$ & $2,0 \%$ \\
Localização do domicílio & Próximo a favelas & $0,195^{* * *}$ & $1,6 \%$ \\
\hline
\end{tabular}




\begin{tabular}{|c|c|c|c|}
\hline & Sem favelas próximas & $0,230 * *$ & $2,7 \%$ \\
\hline Tipo de imóvel & Alugado & $0,180 * * *$ & $2,3 \%$ \\
\hline \multicolumn{2}{|c|}{ Teve gasto com seguro (no mês anterior à pesquisa) } & 0,081 & \\
\hline \multicolumn{2}{|l|}{ Possui Arma } & $0,332 * *$ & $5,1 \%$ \\
\hline \multicolumn{2}{|c|}{ Indicador para ano de 2008} & 0,028 & \\
\hline \multicolumn{2}{|l|}{ Constante } & $-1,64^{* * *}$ & - \\
\hline \multicolumn{2}{|c|}{ Número de Observações } & 5.372 & 5.372 \\
\hline
\end{tabular}

Notas: ${ }^{1}$ A significância dos coeficientes é reportada por meio dos asteriscos: se significante a $10 \%$, *; se significante a $5 \%,{ }^{* *}$; e se significante a $1 \%,{ }^{* * *}{ }^{2}$ O número de observações referentes à condição econômica A1 é muito reduzida e, por implicar em grande colinearidade com a variável A2, foi descartada da regressão. ${ }^{3}$ Reportamos somente os efeitos marginais significantes a, no mínimo, $10 \%$.

Tabela 4: Probit (y=Roubo ou Furto de Automóvel) $)^{1}$

\begin{tabular}{|c|c|c|c|}
\hline & & $\begin{array}{c}\text { Coeficiente } \\
\text { Estimado }\end{array}$ & $\begin{array}{c}\text { Efeito Marginal } \\
\text { da Variável } \\
\text { na Média }{ }^{3}\end{array}$ \\
\hline Sexo & Masculino & 0,074 & \\
\hline \multicolumn{2}{|l|}{ Idade do indivíduo } & $-0,001$ & \\
\hline \multicolumn{2}{|c|}{ Quadrado da idade do indivíduo } & $-0,00003$ & \\
\hline \multirow[t]{3}{*}{ Etnia } & Preta/Parda & $-0,148$ & \\
\hline & Indígena & $-0,280$ & \\
\hline & Amarela & $-0,008$ & \\
\hline Religião & Sem religião & $-0,108$ & \\
\hline Migrante & & $-0,146$ & \\
\hline \multirow[t]{2}{*}{ Estado Civil } & Casado & $-0,041$ & \\
\hline & União Estável & $-0,310^{*}$ & $-3,5 \%$ \\
\hline \multirow[t]{4}{*}{ Condição Econômica } & $\mathrm{A} 1^{2}$ & - & \\
\hline & A2 & $-0,505^{*}$ & $-4,9 \%$ \\
\hline & B1 & $-0,133$ & \\
\hline & B2 & $-0,044$ & \\
\hline \multirow[t]{2}{*}{ Educação } & Superior & 0,238 & \\
\hline & Mestrado/Doutorado & 0,498 & \\
\hline \multirow[t]{6}{*}{ Trabalho } & Aprendiz & $-0,358$ & \\
\hline & Desempregado & $-0,091$ & \\
\hline & Desocupado & $-0,350$ & \\
\hline & Dona de Casa & $-0,126$ & \\
\hline & Aposentado & $-0,069$ & \\
\hline & Estudante & $-0,194$ & \\
\hline
\end{tabular}




\begin{tabular}{lcc}
\hline Teve gasto com seguro (no mês anterior à pesquisa) & $0,165^{*}$ & $2,3 \%$ \\
Possui Arma & $-0,460$ & \\
Consome Bebidas Alcoólicas & $-0,076$ & \\
Frequenta casas noturnas & 0,025 & - \\
Frequenta bares & 0,086 & 1.621 \\
\hline Indicador para ano de 2008 & $-0,055^{* * *}$ \\
\hline Número de Observações & 1.621 & \\
\hline
\end{tabular}

Notas: ${ }^{1}$ A significância dos coeficientes é reportada por meio dos asteriscos: se significante a $10 \%,{ }^{*}$; se significante a $5 \%,{ }^{* *}$; e se significante a $1 \%,{ }^{* * *}{ }^{2}$ O número de observações referentes à condição econômica A1 é muito reduzida e, por implicar em grande colinearidade com a variável $A 2$, foi descartada da regressão. ${ }^{3}$ Reportamos somente os efeitos marginais significantes a, no mínimo, $10 \%$.

Tabela 5: Probit (y=Agressão Física) $)^{1}$

\begin{tabular}{|c|c|c|c|}
\hline & & $\begin{array}{c}\text { Coeficiente } \\
\text { Estimado }\end{array}$ & $\begin{array}{c}\text { Efeito Marginal } \\
\text { da Variável } \\
\text { na Média }{ }^{2}\end{array}$ \\
\hline Sexo & Masculino & $-0,060$ & \\
\hline \multicolumn{2}{|c|}{ Idade do indivíduo } & $-0,015$ & \\
\hline \multicolumn{2}{|c|}{ Quadrado da idade do indivíduo } & 0,00003 & \\
\hline \multirow[t]{3}{*}{ Etnia } & Preta/Parda & 0,042 & \\
\hline & Indígena & $-0,654$ & \\
\hline & Amarela & $-0,538$ & \\
\hline Religião & Sem religião & 0,137 & \\
\hline Migrante & & $-0,066$ & \\
\hline \multirow[t]{2}{*}{ Estado Civil } & Casado & $-0,281 * * *$ & $-1,8 \%$ \\
\hline & União Estável & 0,128 & \\
\hline \multirow[t]{2}{*}{ Educação } & Superior & 0,385 & \\
\hline & Mestrado/Doutorado & $-0,214$ & \\
\hline \multicolumn{2}{|l|}{ Possui Arma } & $0,495 * * *$ & $5,0 \%$ \\
\hline \multicolumn{2}{|c|}{ Consome Bebidas Alcoólicas } & 0,018 & \\
\hline \multicolumn{2}{|c|}{ Frequenta casas noturnas } & 0,070 & \\
\hline \multicolumn{2}{|c|}{ Frequenta bares } & $0,189 * * *$ & $1,3 \%$ \\
\hline \multicolumn{2}{|c|}{ Frequenta shows } & $0,185^{* *}$ & $1,3 \%$ \\
\hline \multicolumn{2}{|c|}{ Participa de festas de rua } & $0,234 * * *$ & $1,7 \%$ \\
\hline \multicolumn{2}{|c|}{ Participa de igreja } & 0,091 & \\
\hline \multicolumn{2}{|c|}{ Pratica esporte } & 0,007 & \\
\hline \multicolumn{2}{|c|}{ Faz alguma atividade física (não esporte) } & $-0,065$ & \\
\hline \multicolumn{2}{|c|}{ Indicador para ano de 2008} & $-0,182 * *$ & $-1,1 \%$ \\
\hline \multicolumn{2}{|l|}{ Constante } & $-1,45$ & - \\
\hline \multicolumn{2}{|c|}{ Número de Observações } & 5.512 & 5.512 \\
\hline
\end{tabular}

Notas: ${ }^{1}$ A significância dos coeficientes é reportada por meio dos asteriscos: se significante a $10 \%$, *; se significante a $5 \%,{ }^{*}$; e se significante à $1 \%,{ }^{* * *}{ }^{2}$ Reportamos somente os efeitos marginais significantes a, no mínimo, $10 \%$. 


\begin{tabular}{|c|c|c|c|}
\hline & & $\begin{array}{l}\text { Coeficiente } \\
\text { Estimado }\end{array}$ & $\begin{array}{c}\text { Efeito Marginal } \\
\text { da Variável } \\
\text { na Média }{ }^{3} \\
\end{array}$ \\
\hline Sexo & Masculino & $-0,375$ & \\
\hline Média de idade no $d$ & nicílio & 0,011 & \\
\hline Quadrado da média & idade no domicílio & 0,0002 & \\
\hline Etnia & Preta/Parda & $-0,180$ & \\
\hline & Indígena & - & \\
\hline & Amarela & 0,905 & \\
\hline Religião & Sem religião & $-0,115$ & \\
\hline Migrante & & 0,211 & \\
\hline $\begin{array}{l}\text { Condição Econômi- } \\
\text { ca }\end{array}$ & $\mathrm{A} 1^{2}$ & - & \\
\hline & A2 & $-0,349$ & \\
\hline & B1 & $-0,179$ & \\
\hline & B2 & $-0,293$ & \\
\hline Mora em casa & & 0,105 & \\
\hline Quantidade de pessc & s na residência & 0,032 & \\
\hline $\begin{array}{l}\text { Tempo de residên- } \\
\text { cia }\end{array}$ & & $-0,001$ & \\
\hline $\begin{array}{l}\text { Localização do } \\
\text { domicílio }\end{array}$ & Próximo a favelas & 0,225 & \\
\hline & Sem favelas próximas & 0,371 & \\
\hline Tipo de imóvel & Alugado & $-0,621^{*}$ & $-15,2 \%$ \\
\hline Teve gasto com segu & o (no mês anterior à pesquisa) & 0,015 & \\
\hline Possui Arma & & 0,260 & \\
\hline Foi vítima de outros & ubos/furtos fora do domicílio & 0,383 & \\
\hline Foi vítima de roubo/f & to de automóvel & $-0,094$ & \\
\hline Quantidade de vezes & que sofreu roubo/furto domicílio & $-0,151$ & \\
\hline Indicador para ano de & 2008 & 0,129 & \\
\hline Constante & & $-1,28$ & - \\
\hline Número de Observa & & 142 & 142 \\
\hline
\end{tabular}

Notas: ${ }^{1}$ A significância dos coeficientes é reportada por meio dos asteriscos: se significante a 10\%, *; se significante a $5 \%,{ }^{* *}$; e se significante a $1 \%,{ }^{* * *}{ }^{2}$ O número de observações referentes à condição econômica A1 é muito reduzida e, por implicar em grande colinearidade com a variável A2, foi descartada da regressão. ${ }^{3}$ Reportamos somente os efeitos marginais significantes a, no mínimo, $10 \%$. 
Tabela 7: Probit (y=Notificação de Roubo/Furto de Automóvel)

\begin{tabular}{|c|c|c|c|}
\hline & & $\begin{array}{l}\text { Coeficiente } \\
\text { Estimado }\end{array}$ & $\begin{array}{c}\text { Efeito Marginal } \\
\text { da Variável } \\
\text { na Média }{ }^{2} \\
\end{array}$ \\
\hline Sexo & Masculino & $-0,439^{\circ}$ & $-11,0 \%$ \\
\hline \multicolumn{2}{|c|}{ Idade do indivíduo } & 0,040 & \\
\hline \multicolumn{2}{|c|}{ Quadrado da idade do indivíduo } & $-0,0003$ & \\
\hline Etnia & Preta/Parda & 0,096 & \\
\hline Religião & Sem religião & $-0,684^{*}$ & $-22,0 \%$ \\
\hline \multicolumn{2}{|c|}{ Número de vezes que teve automóvel roubado/furtado } & 0,072 & \\
\hline \multicolumn{2}{|c|}{ Infrator foi identificado } & 0,608 & \\
\hline \multicolumn{2}{|c|}{ Indicador para ano de 2008} & $-0,128$ & \\
\hline \multicolumn{2}{|c|}{ Constante } & 0,186 & - \\
\hline \multicolumn{2}{|c|}{ Número de Observações } & 118 & 118 \\
\hline
\end{tabular}

Notas: ${ }^{1}$ A significância dos coeficientes é reportada por meio dos asteriscos: se significante a $15 \%,{ }^{\circ}$; se significante a $10 \%,{ }^{*}$; se significante a $5 \%,{ }^{* *}$; e se significante à $1 \%,{ }^{* *}{ }^{*}{ }^{2}$ Reportamos somente os efeitos marginais significantes a, no mínimo, $10 \%$. 